\title{
Legal Aspects In Stroke Management
}

Reza Hajmanouchehri MD,.

Neurologist

*Corresponding Author: Email: h.manouchehri@yahoo.com

Due to increasing the cases of complaint from therapeutic staff, referred to Legal M edicine decided to mention a few examples of these actions and by reviewing them, we want to do something even nothing to prevention. Three cases were given and discussed in this article.

1. Patient is a 68-year-old woman complaining of weakness of her left side and speech disturbance that started about 2 hours earlier, was admitted to hospital at 8 am. Patient with a diagnosis of ischemic stroke in progress is placed in antiplatelet therapy (Plavix 4 initial dose and one per day and an $80 \mathrm{mg}$ aspirin per day) and anti-Coagulation Heparin (initial dose of 6000 units and 1000 units per hour).Patient conflicts with loss of consciousness at 17:45. By doing CT, they have found a large hemorrhage in the right parietal Frontó with severe shift from midline, IVH, SAH. Currently, patient has movement disorders and several cerebral complications.

2. The patient took under angiography because of chest pain. Patient had an unpleasant feeling in organs at the time of angiography and the symptoms have been intensified in the afternoon of that day and conflicted with headache and blurred vision. The next day, he also afflicted with weakness of organs and at 8 am neurology consultation is requested, and according to a neurologist takes M RI. The patient was suffered from speech impairment and right hemiparesis. M RI indicates stroke. Two days later, intravenous heparin begins. The Patient discharged on 31/4/ ... .

3. The patient hospitalized because of headache and weakness of right organs and with a presumptive diagnosis of stroke. Headache had progressive trend. There were not seen certain lesions on the initial CT. 5000 units of heparin with 1000 units of infusion in an hour starts with telephone orders at 8 am. The morning $1 / 8 / \ldots$, he afflicted with loss of consciousness, and transferred to the ICU. In morning experiment, patient's platelet is reported low (47000).The patient gave MRI that had large ischemic lesions of temporoparietal on left with suspicious regions of bleeding and Parietal. Due to low level of platelets $(35,000)$, despite high clinical suspicion for CVST heparin was closed at 11:30. HIT is confirmed in blood consultation and recommended to be cut the anticoagulants. Despite the measures taken, the patient died at 3:45 pm.

In first case, it seems that to start double antiplatelet and intravenous heparin simultaneously was wrong. In the second case, late neurology consultation is a question, though heparin is started too late. But in the third case, progression of the disease has been quite rapid.

Key words: Stroke M anagement, Patient

DOI: $10.7575 /$ aiac.abcmed.ca1.54

A I Published Date: February 2017

AC Peer-review is under responsibility of the 9th Iranian Stroke Congress.

Published by Australian International Academic Centre, Australia

This published work is open access under the CC BY license.

Available online at www.abcmed.aiac.org.au 